\title{
A LITERATURA FANTÁSTICA EM O GATO PRETO DE EDGAR ALLAN POE: UMA ANÁLISE SEGUNDO TODOROV Joelma Mendes Soares BARBOSA ${ }^{1}$
}

\author{
Any Rayra Vieira COSTA2 \\ Lucas Augusto Costa GONÇALVES \\ Antonio de Oliveira Moreira JUNIOR 4 \\ Jessica Silva do NASCIMENTO \\ Wellingson Valente dos REIS ${ }^{\circ}$
}

\begin{abstract}
RESUMO
Edgar Allan é considerado o "pai dos contos de terror", suas abordagens sempre trazem o pessimismo, a morte e o terror ligados ao macabro. A Literatura Fantástica, segundo Todorov (2014), refere-se a um gênero literário que ocorre a partir da hesitação frente a acontecimentos aparentemente sobrenaturais, ao qual abordaremos em "O gato preto", de Poe. O objetivo deste estudo é realizar uma análise a partir dos referenciais apontados sobre as características fantásticas no conto de Poe; a partir da pesquisa bibliográfica, utilizando a metodologia da análise literária do Fantástica de Tzevetan Todorov (2014), apontado as características fantásticas dentro do conto 'O Gato Preto', presente dentro da coletânea 'Histórias Extraordinárias' de Edgar Alan Poe. Ao desenvolver a análise do conto, pudemos observar sua estrutura e o modo como o autor envolve o leitor na obra construindo uma atmosfera de suspense e até mesmo terror. Esse envolvimento do leitor com a obra traz, de uma forma bastante acentuada, o imaginário e as ambiguidades sobre a narrativa, destacando-se como um conto fantástico, de acordo com a obra Introdução à Literatura Fantástica de Todorov. É possível destacar a presença das hesitações geradas no desenvolver da narrativa de Poe e como o público que recebe a obra se sente em uma situação de questionamentos constantes sobre o que pode ser real e o que não poderia. Esse é um ponto essencial na obra para a construção das interpretações. Portanto, a obra de Poe é caracterizada como um conto fantástico visto que há momentos de hesitação, momentos de dúvida, além do imaginário que há durante todo o conto, principalmente no que diz respeito sobre a figura do gato. Além disso, o autor busca sempre o suspense na sua obra envolvendo assim o leitor para o mundo sombrio
\end{abstract}

Palavras-chave: Literatura fantástica. Edgar Allan Poe. O gato preto.

\begin{abstract}
This paper discusses, based on the verbal interaction and genres theory by Bakhtin (2003) and Bakhtin / Volochinov (2006) the contextual use of writing in social network. As for the use of new technologies, it was used Rojo and Barbosa (2015), Rojo (2013) and Araújo and Leffa (2016). The corpus of the comparative analysis is composed of fragments of handwritten letters and Facebook posts produced by 8th grade elementary school students from a public school
\end{abstract}

1 Graduando em Licenciatura em Letras - Língua Portuguesa pelo Instituto Federal de Educação, Ciência e Tecnologia do Pará - IFPA. joelma-122@hotmail.com

2 Graduando em Licenciatura em Letras - Língua Portuguesa pelo Instituto Federal de Educação, Ciência e Tecnologia do Pará - IFPA. anyrayra23@gmail.com

3 Graduando em Licenciatura em Letras - Língua Portuguesa pelo Instituto Federal de
Educação, Ciência e Tecnologia do Pará - IFPA. lukas-k-8@hotmail.com

4 Graduando em Licenciatura em Letras - Língua Portuguesa pelo Instituto Federal de Educação, Ciência e Tecnologia do Pará - IFPA. antonio.o.m.junior@outlook. com

5 Graduando em Licenciatura em Letras - Língua Portuguesa pelo Instituto Federal de Educação, Ciência e Tec- nologia do Pará - IFPA. silvanjessicaifpa@gmail.com.

6 Doutorando em Comunicação, Linguagens e Cultura pela Universidade da Amazônia. Bolsista Prosup/ Capes. Membro do Grupo Interdisciplinar de Pesquisa em Arte, Cultura e Educação (GIPACE/ IFPA/CNPQ) e do Grupo de Pesquisa Interfaces do Texto Amazônico. Professor do IFPA - Campus Belém.
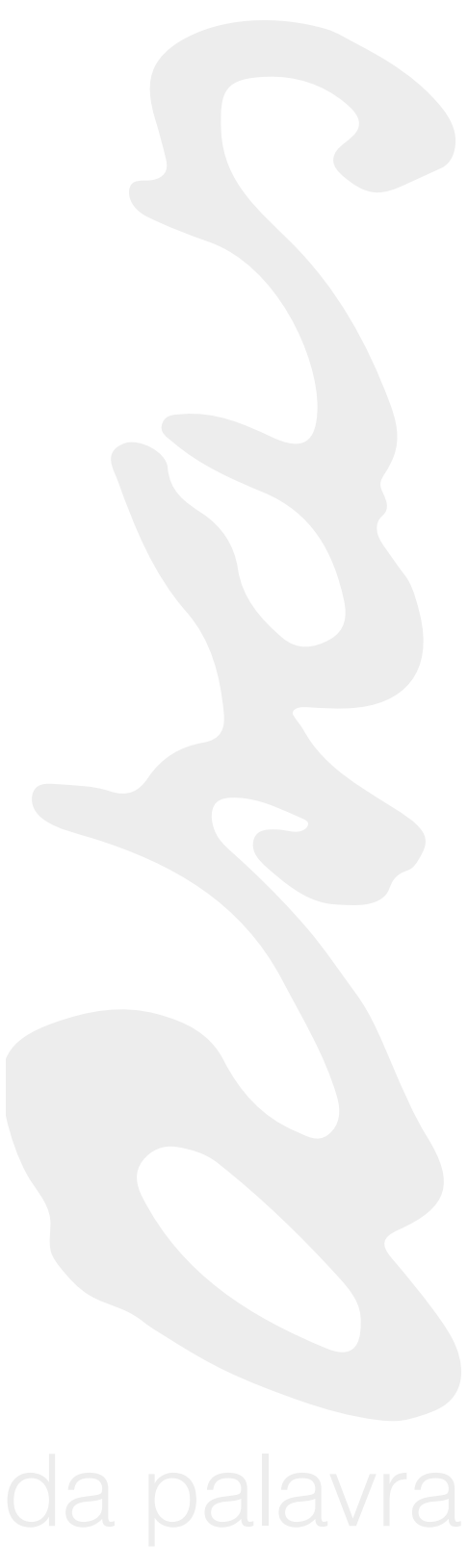

VOL. 14 | N.2 | DEZ. 2017

ISSN 1415-7950 
Graciliano Ramos -E- Biografias: Disponível em: <http//: www.e-biografias.net/graciliano_ramos/> Acesso em: 08 de mar de 2016.

in Belém; here, however, it is concerned with the contributions that the relationship with technology has brought to the expansion of their reading and writing skills. Thus, the focus is the discussion correlated to one of the specific objectives in the master's research of which this paper is a result: (i) to determine how the students behave in a context with the singularities of the virtual world with regard to writing. To this end, Facebook was introduced to position themselves as critical readers and writers, to compare what differentiates their critical online position from conventional writing, thus contrasting the contexts of production and differences that this implies in the lexical choices. The results point to a change in posture when the learner-author subject is confronted with a linguistic situation in which, in fact, there is a real interlocutor and the writing becomes significant; also makes different grammatical, lexical and phraseological choices when structuring its statement in front of different interlocutors, which points us a way for the significant use of technologies in Portuguese classes.

Keywords: Verbal interaction. Facebook. Learner-author subject.

\section{INTRODUÇÃO}

A origem da Literatura fantástica se deu em meados do século XVII, se desenvolveu no século XIX com a instauração do real e do imaginário a partir do positivismo e perdura até hoje. A narrativa fantástica gera no leitor uma atmosfera de incertezas, há uma constante dúvida sobre os fatos narrados. Dessa forma, "o fantástico é a hesitação experimentada por um ser que só conhece as leis naturais, face a um acontecimento aparentemente sobrenatural". (TODOROV, 2014, p. 31).

A narrativa fantástica utilizada como objeto deste trabalho faz parte da obra "Histórias Extraordinárias" (2012) do autor americano Edgar Alan Poe, conhecido mundialmente como "o pai dos contos de terror". O exemplar comtempla cinco contos, são eles: O enterro prematuro, A queda da casa de Usher, Willian Wilson, O poço e o pêndulo e $\mathrm{O}$ gato preto, objeto em análise. O conto aborda de maneira sombria e misteriosa a relação de dois personagens em especial, o homem com transtornos de comportamento devido ao alcoolismo e seu gato de estimação. Desde o princípio, a história suscita dúvida ao leitor, visto que o narrador começa advertindo-o de que não há obrigação alguma de acreditarem em seus relatos sobre os eventos macabros ocorridos em sua vida.

A partir de uma pesquisa bibliográfica o trabalho tem como objetivo realizar uma análise do conto supracitado, com base no referencial teórico adotado, especialmente Tzevetan Todorov em "Introdução à literatura fantástica" (2014). Especificaremos no decorrer da análise do conto as características do fantástico, de acordo com o teórico destacado, a saber: a hesitação e a ambiguidade, assim como os aspectos semânticos e sintáticos.

$\mathrm{O}$ artigo se estrutura em quatro seções. Na primeira seção destacaremos brevemente aspectos gerais e relevantes da biografia do autor e sua produção. $\mathrm{Na}$ segunda seção o foco é apresentar uma síntese do conto "O gato preto", bem como a explanação dos elementos estruturais (personagens, ponto de vista, espaço, descrição e diálogo) da narrativa, segundo Massaud Moisés. A seção seguinte adentra especificamente na análise da narrativa, detalhando o fantástico segundo Todorov e suas categorias, além de demonstrar como a teoria se aplica ao conto de Poe. E, por último, nas considerações finais, apresentaremos uma síntese dos resultados obtidos a partir da análise.

\section{EDGAR ALLAN POE: VIDA \& OBRA}

Edgar Allan Poe nasceu em 19 de janeiro de 1809, em Boston, Massachusetts (EUA) uma cidade com aproximadamente 30 mil habitantes, e em uma família escocês-irlandesa. Filho de atores pobres, Edgar e seus irmãos conheceram muito 
cedo a miséria e a dor da perda. Dois anos após o desaparecimento de seu pai biológico - pouco se sabe a respeito dele - e com a morte da mãe, vítima de tuberculose, as três crianças ficam órfãs e é nesse momento que Edgar é adotado por John Allan e sua esposa Frances, incorporando assim o outro sobrenome. Dos seis aos onze anos Poe mora com a família em Londres, na Inglaterra, visto que seu pai tenta se reestabelecer comercialmente, porém não obtendo sucesso nessa tentativa a família retorna aos Estados Unidos.

Contudo, é na adolescência que fatos estranhos começam a marcar sua vida. Com aproximadamente 14 anos Poe dedica à mãe de um amigo o poema "Para Helena", que após pouco tempo morre vítima de uma doença mental. As tragédias na vida dele continuam e além de passar por muitos transtornos que influenciaram até em seu comportamento, ele vê sua irmã mais nova, Rosália, morrer em decorrência de uma paralisia e perde também sua mãe adotiva que sofria de várias doenças. Acredita-se que a morte de sua mãe biológica seria o início de perdas que viria a se espalhar por sua natureza ao longo de sua vida. Aos 27 anos, Poe casa-se secretamente com sua prima Virgínia Cleem, a quem chamava de Sissy. A partir de então, sua pequena família ficou a resumida a Muddy - sua tia - e sua esposa.

Em 1833, Edgar ganha um prêmio literário com o conto "Manuscrito encontrado numa garrafa" e a partir de então passa a se dedicar à prosa. Ele também trabalhou em várias revistas, contudo, mesmo sendo muito dedicado ao objetivo de se tornar um escritor profissional, Poe conheceu apenas alguns momentos de sucesso. Não obtendo tanto êxito, viveu juntamente com sua família uma vida de pobreza. Não ter alcançado o reconhecimento que tanto almejava, lhe ocasionou muitas tristezas, assim como o alcoolismo e uma personalidade perturbada.

Em 30 de janeiro de 1847, com apenas 25 anos, Virgínia Clemm Poe veio a óbito, vítima de tuberculose, somando assim mais uma triste perda na vida de Edgar. Em sua viuvez, Allan Poe reencontra Sarah Elmira Royster, seu amor de juventude e em agosto de 1849 ela aceita casar-se com ele - 22 anos após o primeiro pedido de casamento por parte do escritor - porém ele é encontrado morto em uma taberna de Baltimore. A causa de sua morte permanece em mistério.

Com contos que refletiam muito a sua própria realidade, Edgar Allan Poe é considerado o pai das histórias modernas de detetive e um dos precursores da literatura fantástica e das histórias de ficção científica. Além de escritor, foi também poeta, romancista e o primeiro verdadeiro crítico literário americano.

\section{O GATO PRETO DE EDGAR ALLAN POE}

A obra "Histórias Extraordinárias", de Edgar Allan Poe, publicada pela Editora Martin Claret em 2012 e traduzida por Eliane Fittipaldi Pereira e Katia Maria Orberg, foi o exemplar utilizado para a realização deste trabalho. É composta por cinco contos, sendo eles: O enterro prematuro, A queda da casa de Usher, Willian Wilson, $\mathrm{O}$ poço e o pêndulo e o gato preto, o objeto de análise da pesquisa. Narrado em primeira pessoa, $\mathrm{O}$ gato preto traz a intrigante história de um homem que de antemão diz não esperar que as pessoas acreditem no que ele vai contar, visto que até seus próprios sentidos rejeitam sua própria evidência. A priori, o narrador em questão confessa seu amor por animais e se diz sortudo por ter encontrado uma esposa que compartilha desse mesmo sentimento.

Entre vários bichos, ele escolhe Plutão, um gato preto, como o seu favorito. Porém, essa afeição parece não durar tanto tempo e algumas mudanças de humor, principalmente em decorrência de seu problema com álcool, começam a alterar o comportamento - até então amigável - entre dono e animal de estimação. Após mais uma noite regada a bebida, ao chegar em casa, o homem percebe que o felino estava com medo, e em um ato de crueldade pega um canivete e fura um de seus olhos. Em um misto de horror e remorso, o narrador experimenta um sentimento fraco e ambíguo pelo ato cometido e logo estava a beber para se livrar das lembranças. O gato recuperou-se, porém, ficou cada vez mais arredio e seu comportamento ocasionou 
mais um momento de fúria ao seu dono, que a sangue-frio, amarrou uma corda no pescoço do gato e o enforcou em uma árvore. Na mesma noite em que o crime foi cometido, misteriosamente sua casa pegou fogo.

Após o ocorrido, o narrador sente saudades de Plutão e procura um novo animal de estimação. Em mais uma noite de embriaguez, encontra em uma taverna um gato preto e o leva para casa, assim que sua esposa o vê, passa a ter um carinho especial pelo bichano e vice-versa. Isso, no entanto, desperta imediatamente aversão do narrador para com o animal. Para acentuar mais ainda o sentimento de raiva, ele descobre, no dia seguinte, que assim como Plutão, o "novo" gato havia sido privado de um olho. Ao passo que a repulsa do homem aumentava, o gato tornava-se cada dia mais apegado a ele. Um fato que causou horror ao homem foi quando sua mulher percebeu que o gato em questão possuía em volta do pescoço uma mancha branca, única diferença entre os dois felinos. A mancha, para seu total desespero, lhe lembrava uma forca e, seu temperamento - que já não era bom - piorou consideravelmente, até mesmo com sua esposa. Em um dia, após descerem ao porão, para realizar uma tarefa doméstica, o homem fica irritado porque o gato os segue e quase o derruba. Nesse momento usa todo seu ódio e levanta o machado na direção do gato, sua esposa tenta impedi-lo e é atingida voluntariamente. Após o assassinato, o homem se empenha na tarefa de ocultar o corpo e se sente orgulhoso pelo "crime perfeito".

Quatro dias depois do crime, o homem sentia- se livre do gato, pois desde então o animal havia desaparecido. Inesperadamente um grupo de policiais apareceu em sua casa. Convencido de que nunca iriam descobrir o que havia feito, ele os levou até o porão e quando os policiais já estavam indo embora, o homem orgulhoso demais de seu feito, começou a mostrar com sua bengala, quão resistente eram as paredes do local. Ao bater na parede, no lugar exato onde escondeu o corpo da esposa, ouviu-se um longo e alto berro totalmente anômalo e inumano. Assustados os policias examinaram a parede e em seguida, um cadáver ensanguentado e em estado de decomposição surgiu. E para o total horror do homem, em cima da cabeça de sua esposa estava o gato preto. Ele havia emparedado o monstro dentro da tumba. $\mathrm{O}$ conto possuí quatro personagens. O protagonista que narra a história em primeira pessoa, demonstrando-nos o ponto de vista e passando suas dúvidas quanto a veracidade dos fatos, anulando a distância com o leitor e deixando a impressão de tê-lo como exclusivo confidente do caso (MOISÉS, 1999, p. 69), recurso esse utilizado para provocar a hesitação no leitor. A esposa, que é a vítima derradeira da violência do protagonista, funciona como pano de fundo para a narrativa e acaba não participando do diálogo que nucleia o conto. $\mathrm{O}$ gato preto Plutão, animal preferido do protagonista que é vítima dos seus maus tratos e o misterioso gato preto que aparece posteriormente causando a prisão do protagonista. Fundamentado nos tópicos apontados observamos que a ação é focada em dois personagens, o homem e o gato preto.

Para Moisés (1999) o espaço é o lugar onde as personagens circulam, e é sempre de âmbito restrito. No geral, uma rua, uma casa, e, mesmo, um quarto de dormir ou uma sala de estar. Na obra "O Gato Preto" os fatos ocorrem em duas residências, uma taverna e um porão, os quais não são descritos minunciosamente. A primeira residência é evidenciada quando o narrador personagem relata os comportamentos do gato após ter tido um olho arrancado, vejamos: "Andava pela casa como de costume, mas, como era de esperar, fugia com extremo terror a minha aproximação" (POE, 2012, p. 24). A segunda residência, após a mudança, devido ao incêndio, vemos no trecho a seguir: "Ao chegar à casa, ele imediatamente se familiarizou com ela e se tornou desde logo grande favorito de minha mulher" (POE, 2012, p. 27). O terceiro espaço é apresentado no momento em que o homem está em busca de um novo animal e encontra um "outro" gato, esse encontro é registrado em uma taverna, visto que o homem pergunta ao taberneiro quem é o dono do gato que lá está, “[...] imediatamente, tentei comprá-lo ao taverneiro, mas este disse que não lhe pertencia o animal, nada sabia a seu respeito e nunca o vira antes" (POE, 2012, p. 27). O quarto espaço é um dos cômodos da segunda residência, o porão, e é apresentado após o assassinato que o narrador personagem comete. $\mathrm{O}$ crime é registrado no porão da 
média emparedavam suas vítimas. Para um objetivo semelhante estava o porão bem adaptada." (POE, 2012, p.30)

A descrição, para Moisés (1999) consiste na enumeração de características próprios dos seres, animados ou inanimados, e coisas, como, por exemplo, a descrição da natureza, das ruas, das pessoas, dos automóveis. Durante a trama do conto a descrição é observada quando Plutão é apresentado ao leitor como um gato único, inconfundível, majestoso, demonstrado no seguinte trecho: "Tínhamos pássaros, peixes dourados, um lindo cão, coelhos, um macaquinho e um gato. Este último era um belo animal, notavelmente grande, todo preto e de uma sagacidade de espantar" (POE, 2012, p.22).

O diálogo é a marca fundamental dentro de uma obra, Moisés (1999) classifica-o em quatro tipos que podem ser considerados: Diálogo direto, representado por um discurso marcado por aspas ou travessões, encontra-se fragmentos do diálogo direto quando ocorre o incêndio na casa e gritam para avisar sobre o desastre, "Na noite do dia no qual pratiquei essa crudelíssima façanha fui despertado do sono pelos gritos de: 'Fogo! '” (POE, 2012, p.25); diálogo indireto, será o resumo das falas dos personagens de forma narrativa e é encontrado na resposta negativa do taverneiro "este disse que não lhe pertencia o animal, nada sabia a seu respeito e nunca o vira antes”. (POE, 2012, p. 27); diálogo indireto livre consiste na fusão entre terceira pessoa e primeira pessoa na narrativa; por fim, diálogo (monólogo), que é o pensamento de um personagem como "embora tivesse o desejo ardente de matá-lo com uma pancada, era impedido de fazê-lo, em parte por me lembrar de meu crime anterior mas, principalmente - devo confessá-lo sem demora -, por absoluto pavor do animal". (POE, 2012, p. 27).

\section{A Literatura FANTÁSTICA EM "O GATO PRETO" DE EDGAR ALLAN POE}

Todorov (2014) afirma que o fantástico se define a partir da relação entre o real e o imaginário, ocorre na incerteza de transitar entre uma resposta e outra. É a hesitação experimentada por um ser que só conhece as leis naturais, seja o leitor ou o personagem, face a um acontecimento aparentemente sobrenatural. "No verdadeiro fantástico, fica sempre preservada a possibilidade exterior e formal de uma explicação simples dos fenômenos, mas ao mesmo tempo está explicação é completamente privada de probabilidade interna" (SOLOVIOV apud TODOROV, 2014, p.31) ou seja, há um fenômeno incomum que pode se explicar de duas maneiras: por meio de causas de tipo natural e sobrenatural. A possibilidade de se hesitar entre os dois, cria o efeito fantástico.

A hesitação do leitor é, pois, a primeira condição do fantástico (TODOROV, 2014, p.37), além disso, "pode ser igual experimentada por uma personagem; desta forma o papel do leitor é, por assim dizer, confiado a uma personagem e ao mesmo tempo a hesitação encontra-se representada, [...] o leitor real se identifica com a personagem." (TODOROV, 2014, p. 39). O teórico ainda afirma que se uma obra provoca a hesitação do leitor imediatamente ocasiona a hesitação do personagem, contudo existem exceções, nas quais o leitor não encontrará a hesitação representada no texto, diremos então, nesse caso, que é uma condição facultativa do fantástico (TODOROV, 2014, p. 73). No conto em análise veremos que a hesitação se dará tanto por parte do personagem, por isso representada, como por parte do leitor. Vejamos as exemplificações de hesitação nos trechos da obra. Neste primeiro fragmento verificamos que o personagem principal hesita ao narrar os fatos que julga tão incoerentes que seus próprios sentidos, tem dificuldade em aceitar:

Para a muito estranha embora muito familiar narrativa que estou a escrever, não espero nem solicito crédito. Louco, em verdade, seria eu para esperá-lo, num caso em que meus próprios sentidos rejeitam seu próprio testemunho. Contudo, lou- VOL. 14 | N.2 | DEZ. 2017 
co não sou e com toda a certeza não estou sonhando. (POE, 2012, p. 21)

Neste segundo trecho a hesitação se dará por meio do leitor, quando o narrador personagem, descreve seu encontro com o "outro" gato que aos poucos vai mostra-se cada vez mais parecido com o gato que ele enforcou a pouco tempo. O que leva o leitor a questionar se seria Plutão ou não? Ou, como o bichano sobreviveu? Seria mesmo outro gato idêntico? É a incerteza sobre os acontecimentos que nos leva ao fantástico:

Uma noite, estava eu sentado meio aturdido num antro [...], a minha atenção foi despertada por um objeto preto que repousava no topo de um dos enormes toneis de gin ou de rum [...] Aproximei-me e toquei-lhe com a mão. Era um gato preto, um gato enorme, tão grande como Plutão e semelhante a ele em todos os aspectos menos num. Plutão não tinha sequer um único pêlo branco no corpo, enquanto este gato tinha uma mancha branca, grande mas indefinida[...]Era este, pois, o animal que eu procurava. Imediatamente propus a compra ao dono, mas este nada tinha a reclamar pelo animal, nada sabia a seu respeito, nunca o tinha visto até então. [...] quando me preparava para ir para casa, o animal mostrou-se disposto a acompanhar-me. Permiti que o fizesse[..]. Quando chegou a casa, adaptou-se logo e logo se tornou muito amigo da minha mulher pela minha parte, não tardou em surgir em mim uma antipatia por ele. Lentamente, a pouco e pouco, esses sentimentos de desgosto e de aborrecimento transformaram-se na amargura do ódio. Evitava o animal; [...] O que aumentou, sem dúvida, o meu ódio pelo animal foi descobrir, na manhã do dia seguinte a tê-lo trazido para casa, que, tal como Plutão, tinha também sido privado de um dos seus olhos. (POE, 2012, p. 26-27).

Todorov (2014, p. 39) destaca ainda, no processo de definição do fantástico, o aspecto verbal do texto, "mais exatamente, ao que se chama 'visões': o fantástico é um caso particular da categoria mais geral da "visão ambígua"'. De acordo com essa característica, esse aspecto verbal possibilita ao leitor uma interpretação dúbia dos fatos, como descreve Perieni (2005):

O aspecto verbal é dividido em enunciação (narrador) e enunciado (narração). Para Todorov, o narrador do fantástico deve ser representado, ou seja, um personagem envolvido com os fatos ou um narrador que focalize apenas a ótica dos personagens, possibilitando uma interpretação ambígua dos acontecimentos. A enunciação, que diz respeito ao corpo do texto, deve ser permeada de mecanismos que mantenham a ambiguidade da leitura. (PERIENI, 2005, p.205).

Além desse aspecto, o teórico afirma que a composição do fantástico também se refere aos aspectos sintático e semântico. O primeiro diz respeito a pontos altos da narrativa referentes, de acordo com Todorov $(2014$, p.39) "à apreciação feita pelas personagens sobre os acontecimentos da narrativa [...]"; podemos destacar o espanto, a revelação, assombro, etc. $\mathrm{O}$ teórico destaca que essas apreciações poderiam ser declaradas 'reações', por oposição às 'ações' que se formam habitualmente (TODOROV, 2014, p.39).

O aspecto semântico está ligado aos símbolos, caracteres, significados, por exemplo, pode-se fazer menção sobre a figura do gato preto que é associado a, de acordo com algumas simbologias, bruxaria, magia negra, servidor do inferno etc. 
Trata-se, então, "de um tema representado, o da percepção e sua notação". (TODOROV, 2014, p. 39)

Sobre a variedade do fantástico, o teórico destaca as importantes características que resultam na hesitação e afirma que esta se encontra entre o real e o imaginário. Na primeira situação, duvida-se da compreensão que se teve sobre os fatos ocorridos, já no segundo, surge o questionamento se as situações sucedidas foram apenas fruto da imaginação. (TODOROV, 2014, p. 42). No trecho do conto veremos essa hesitação presente devido os aspectos duvidosos quando o narrador personagem descreve o fato da mancha no pelo do gato que lembrava uma forca:

O leitor terá de recordar que essa mancha, embora grande, havia se mostrado originalmente muito indefinida; porém, mediante vagarosas gradações - gradações quase imperceptiveis, e que por longo tempo minha Razão lotou por rejeitar como fruto de imaginação - assumira, finalmente, uma rigorosa precisão de contornos. Era agora a representação de um objeto que tremo em nomear - e por isso, acima de tudo, nutria ódio, $e$ pavor, e teria me livrado do monstro caso ousasse - era agora, afirmo, a imagem de uma coisa hedionda - de uma coisa macabra - do PATÍBULO! - as, pesaroso e terrivel maquinismo de Horror e de Crime - de Agonia e de Morte! (POE, 2012, p. 87).

A ambiguidade ocorre devido dois procedimentos de escrita que permeiam o texto, são eles: o imperfeito e a modalização. Todorov prossegue destacando que a modalização se refere a locuções que podem mudar a relação entre o sujeito da enunciação e o enunciado, remete à dúvida, incerteza, a expressão "talvez" é um exemplo. No que se refere ao imperfeito, o autor destaca que este possui um sentido semelhante, no remetendo a um fato ocorrido no passado, no entanto, sem certeza se foi concluído, por exemplo, "Parecia me que [...]", "Acreditei cair [...]", "sentia-me". (TODOROV, 2014, p. 43-44). Podemos notar que no conto em análise o narrador declara que "talvez, algum intelecto haverá de surgir para reduzir minha fantasmagoria ao lugar-comum [...]" (POE, 2012, p. 81), ou seja, essa estratégia narrativa gera no leitor a incerteza sobre o que se sucederá.

Observa-se que esses procedimentos de escrita são utilizados para trabalhar a narrativa deixando a hesitação mais acentuada, sem elas não poderíamos adentrar no terreno do fantástico. Todorov (2014) deixa bastante clara essa informação quando diz que "se essas locuções estivessem ausentes, estaríamos mergulhados no mundo do maravilhoso, sem qualquer ligação com a realidade cotidiana, habitual; por meio delas, somos mantidos nos dois mundos ao mesmo tempo." (TODOROV, 2014, p. 44).

\section{CONSIDERAÇÕES FINAIS}

Concluímos então que a partir da definição de Todorov $(2014$, p.31) que afirma que o fantástico se define a partir da relação entre o real e o imaginário, o conto "O Gato Preto" de Edgar Allan Poe é caracterizado como fantástico puro, visto que há o momento de hesitação, do leitor e do narrador personagem, o momento de dúvida, os símbolos, através da figura do gato preto, caracteres, significados e o imaginário que perdura durante toda a obra, sem jamais adentrar no campo do Maravilhoso ou do Estranho, principalmente no que diz respeito a figura do gato. Além disso, o autor busca manter uma atmosfera mórbida de suspense e mistério durante toda a sua obra, transportando o leitor para um universo sombrio. 


\section{REFERÊNCIAS}

BLOOMFIELD, Shelley Costa. O livro completo de Edgar Allan Poe: a vida, a época e a obra de um gênio atormentado. São Paulo: Madras, 2008.

GAMA, Vanderney Lopes da. A tradição literária do fantástico todoroviano: uma questão de gênero. Revista Semioses, Rio de Janeiro, v. 1, n. 11-21, 2010.

MOISÉS, Massaud. A Criação Literária: prosa. Belo Horizonte: Editora UFMG, 1999.

PERIENI, Fabio Lucas. Fantástico e alegoria em A mão perdida na caixa de correio, de Ignácio de Loyola Brandão. Revista Organon, São Paulo, v. 19, n. 38-39,2005.

POE, Edgar Allan. Histórias Extraordinárias. São Paulo: Martin Claret Ltda, 2012.

SIERRA I FABRA, Jordi. Poe: a vida brilhante e sombria de um gênio. São Paulo: Ática, 2011

TODOROV, Tzvetan. Introdução à Literatura Fantástica. São Paulo: Perspectiva, 2014. 